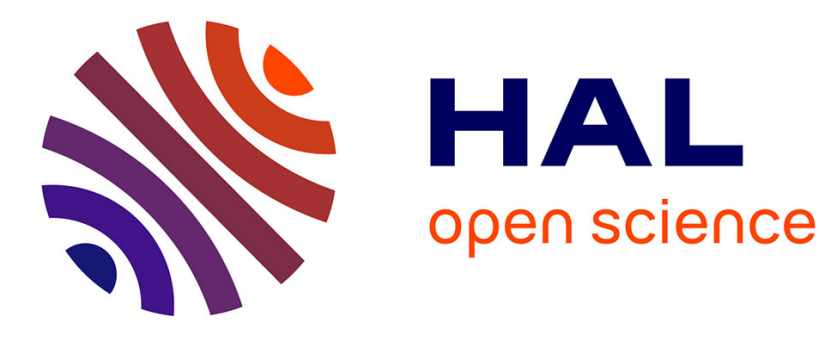

\title{
Understanding Microgrids and Their Future Trends
}

Ritu Raj Shrivastwa, Ahmad Hably, Kaouthar Melizi, Seddik Bacha

\section{To cite this version:}

Ritu Raj Shrivastwa, Ahmad Hably, Kaouthar Melizi, Seddik Bacha. Understanding Microgrids and Their Future Trends. ICIT 2019 - IEEE International Conference on Industrial Technology, Feb 2019, Melbourne, Australia. 10.1109/ICIT.2019.8754952 . hal-01973205

\section{HAL Id: hal-01973205 https://hal.science/hal-01973205}

Submitted on 8 Jan 2019

HAL is a multi-disciplinary open access archive for the deposit and dissemination of scientific research documents, whether they are published or not. The documents may come from teaching and research institutions in France or abroad, or from public or private research centers.
L'archive ouverte pluridisciplinaire HAL, est destinée au dépôt et à la diffusion de documents scientifiques de niveau recherche, publiés ou non, émanant des établissements d'enseignement et de recherche français ou étrangers, des laboratoires publics ou privés. 


\title{
Understanding Microgrids and Their Future Trends
}

\author{
Ritu Raj Shrivastwa, Ahmad Hably, Kaouthar Melizi, Seddik Bacha \\ Univ. Grenoble Alpes, CNRS, Grenoble INP* \\ GIPSA-lab, G2Elab 38000 Grenoble, France \\ *Institute of Engineering Univ. Grenoble Alpes \\ ritu-raj.shrivastwa@grenoble-inp.fr, ahmad.hably@grenoble-inp.fr
}

\begin{abstract}
Depletion of natural resources to meet power demands has revolutionized the use of Renewable Energy Sources (RESs).The paradigm shift from the centralized to distributed control is witnessed due to the Microgrids. Different configurations using smart grids and Microgrids are expected to ensure grid stability and security.Eventually, electricity market is subjected to change due to the projected changes in the grid architecture. This paper is a review on the Microgrids, its elements and the controllability. This paper discusses the major issues in the Microgrids, the factors affecting the choice of the Microgrid type and also various generation sources and their combination for reliable power quality and control. Recent developments with future trends are also addressed in this paper.
\end{abstract}

Index Terms-Microgrids, distributed generation, Microgrid architecture, electricity markets, optimization

\section{INTRODUCTION}

Changes in the global climatic conditions has raised a demand in the use of RESs irrespective of the changes in the control and efficiency of the existing utilities. Demand side installations of distributed generation (DG) sources marks a upcoming change to the electricity markets due to the increasing number of market players. Passing over an active role to the Distribution Network Operators (DNOs) changing the control from centralized to distributed, the market gives opportunities for new players like ancillary service (AS) providers to participate in the transactions. However, intermittency of the RESs pose a threat to stability of the grids. Also, penetration of power sources should be done at specific nodes to avoid voltage imbalances [1]. Hedging of the investment in the electricity market is becoming easier with the introduction of the Microgrids enabling the players to engage in different markets.

Major classifications of Microgrids usually divides them as physical Microgrids (PM) and commercial Microgrids (CM). In PM all the sources and the loads are connected through a point of common coupling (PCC), where as the concept of PCC does not exist in CM which means that the loads and sources can lie on either side of the LV or MV lines. The PM are used for meeting the technical demands and the supply demand balance in the grid however, the term CM is used often to meet the financial aspects of the electricity market. Also, synchronous and non-synchronous sources being used in the Microgrids affect the stability drastically depending upon their share.
This paper is organized as follows. In section II we discuss about the types of the Microgrids followed by section III and section IV where different sources and storages are discussed. Effect of the Microgrids on the power grids is discussed in section V. Section VI and VII talks about the economics and the optimization and control of Microgrids and finally the review is concluded with the future prospects in section VIII.

\section{TYPES OF MICROGRIDS}

The choice of Microgrids highly depends upon the criteria like stability, connectivity, total capacity, available sources and available infrastructure.

Connectivity with grid has a vital role to play in the stability and choice of current for operation in the Microgrid. Due to the massive existing infrastructure of the $\mathrm{AC}$, most of the grid connected Microgrids tend to operate in the AC (alternating current) domain however, the isolated Microgrids preferably operate in LVDC which results in low losses and also has a possibility to be connected to the grid in the future with advanced PE devices. However, depending on the sources employed in the microgird, connectivity may affect the overall inertia of the grid to which the Microgrid is connected.

Stability can be a major game changer in the deployment of the Microgrids. Strategic control structures are needed to counter the non-synchronous nature of the generating sources. Exchanges through tie lines are possible for better stability in the Microgrids because of which the grid connected Microgrids tend to have better stability than those of islanded operations. Use of secondary storages with RESs can significantly improve the delivery profile of the system.

Total capacity of the Microgrid also determines the threat of imbalance due to small changes. The load-generation ratio is a critical balance in low capacity grid. However, this consideration significantly changes with the Microgrids operating under large capacities of both generation and consumption because larger is the generation and load of the system greater is the inertia and lesser is the swing due to the change in the loading conditions or the generated power. Similarly, the capability of the available sources to control deviations in grid is highly considered in designing. Sources like PV and wind are uncontrollable and thus are put to the category of nonsynchronous and poses a threat to the stability. Also, some generate DC and others generate $\mathrm{AC}$ and also at different levels, these factors also determines the choice of the operating voltage and current. However, if the available infrastructure 
is of $\mathrm{AC}$ then preferably the installed sources will deliver AC power for consumption. But new Microgrids which are recently being constructed can be made to work efficiently with DC power with LVDC.

Based on the above discussions, the Microgrids can be classified into DC, AC and Hybrid Microgrids.

The term AC Microgrids, as presented in figure 1, refers to the Microgrids with AC power. Most of the installed or available infrastructure corresponds to AC. All the loads and sources are connected at the point of common coupling (PCC). Exchange of power among the sources and loads and also grid connected operation can be done through the PCC. In terms of grid stability, with the advanced PE converters with the capability of regulating the active and reactive power, $\mathrm{AC} \mathrm{Mi-}$ crogrids are feasible to participate. Also, conventional sources like diesel generators can also be utilized in cooperation with the other sources to stabilize the grid under disturbances. Most of the protection devices manufactured by the companies focus on the $\mathrm{AC}$ systems, thus feasibility of having a AC Microgrid is always more in today's scenario. Due to high use of PEs inverters, the DC power generated by the sources can be efficiently converted to $\mathrm{AC}$ power to be used in the $\mathrm{AC}$ grids [2].

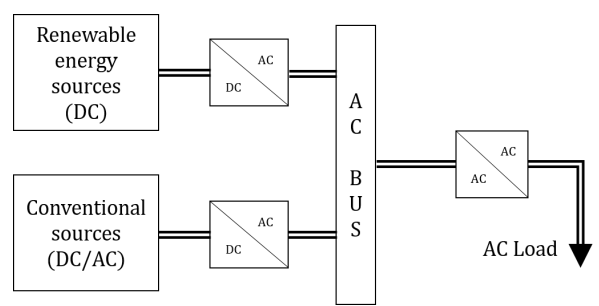

Fig. 1. Schematic representation of an AC Microgrid

Sources like PV systems, a major proportion of the sources in DGs, generate power in DC. Also, through the use of DC generators in the micro wind and micro hydro units can be an option towards DC Microgrids. In literature, many authors have suggested use of control mechanisms for the peer power exchange for Microgrid. Smart power routers (SPR) in [3] can be a good substitute to the centralized Microgrid central controller (MCC) [4]. SPRs can play a vital role in the future grids in not only controlling the power flow but also in management of the cost of the electricity of the owner. In such grids, the loads are usually all DC loads and the level of operating voltage can also vary in the range $48 \mathrm{~V}$ to $310 \mathrm{~V}$ or other levels depending upon the loads, communication system used or the designers. In comparison to the AC Microgrid, the DC Microgrid is simpler as it does not have physical quantities like reactive power, and frequency. Also, phase consideration is absent which makes the coupling of DC devices and sources simpler. A simple representation of the DC Microgrid can be depicted as in figure 2 .

According to the data from world bank, approximately $14 \%$ of the world's population untill 2016 had no access to electricity [5]. The reasons being economical, political as well

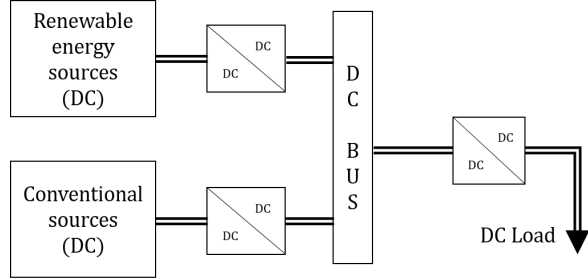

Fig. 2. Schematic representation of a DC Microgrid

as technological. The extreme expense on the power power lines is among the reasons to have an AC or DC Microgrid for these places [6]. In hybrid Microgrids, both AC and DC loads and sources can be present [6]. PCC will have an important role in controlling the power flow. In [7], operation with AC/DC loads and generation is portrayed. Different control algorithms can be used depending upon the location of the installations [8]. Home Area Network (HAN), or Wide Area Network (WAN) being used by the Smart Home Management Systems or MCC respectively are some wide examples of modern day architectures of the Microgrids. Also, the control mechanism of hybrid grids is complex than that of simply AC or DC Microgrid due to the increase in the control parameters like reactive power, phase compensation and frequency [9]. Several authors have studied the real time operation of the hybrid Microgrid and analysed the control structures as in [10]. In view of this explanation, figure 3 is how a hybrid Microgrid structure looks like.

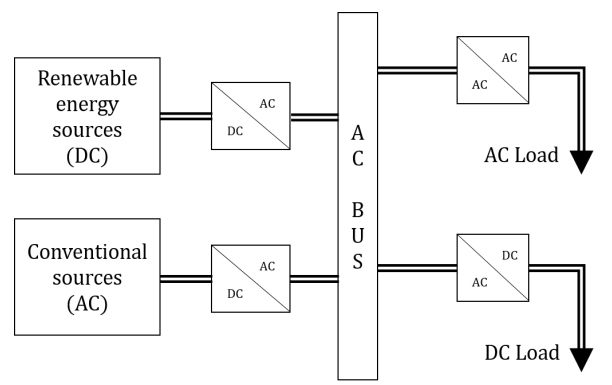

Fig. 3. Schematic representation of a Hybrid Microgrid

\section{Distributed Generation Sources}

DGs are gaining larger proportion of the distribution network creating paradigm shift from centralized to distributed. Also, integration of Power Electronic (PE) converters with PV systems as in [11] and [12], the landscape of DG is changing drastically. Also, new micro-hydro and wind turbines are also contributing to it. However, DG sources are not all stable or continuous sources and they highly depend on climate and geographical locations. The intermittency of the sources affect the grid stability at large in the Microgrids. Use of storage systems alongside RESs are a better way to supply stable and constant power [13] besides increasing the overall cost of the unit. Primary sources in DG are PV systems, microwind, micro-hydro, biomass and diesel generators divided into 
two major categories based on the basis of participation in grid control i.e. synchronous and non-synchronous sources. Intermittency in the wind speed leads to unprecidented generation from wind leading to low grid inertia. Where as, the sources like diesel and hydro can be controlled to respond to the power fluctuations and are referred to as synchronous sources maintaining grid inertia.

\section{A. Photovotaic $(P V)$ systems}

Sun's heat and light has been a source of energy for humankind for many years. Use of solar insolation for generation of electric power is a major breakthrough for DG. In [14], the authors have discussed about the scenario of solar and its advantages in comparison to the conventional power sources. Advanced PE converters have shaped a way for solar power in the grids. Large scale solar farm to rooftop solar installations are widely in application throughout the world. In most of the parts of the world, insolation is approx. $1000 \mathrm{~W} / \mathrm{m}^{2}$. But due to low efficiency of the solar panels, the tapped energy is only $20 \%$ of the the total insolation. Rooftop solar panels are bringing a paradigm shift in the distribution network with increasing installations and allowing the consumers home to grid services. In order to obtain the capacity of the solar for any specific application, Equation 1 can be used:

$$
P_{\text {solar }}=E_{\text {req }} /\left(\eta H_{\text {sun }}\right)
$$

where, $P_{\text {solar }}$ is the required capacity of the solar panels. $E_{r e q}$ is the energy required for the whole duration and $\eta$ is the efficiency of the panels with $H_{\text {sun }}$ being the hours of sunlight in that location [15]. Standard solar panel manufacturers manufacture the panels in the range of $250 \mathrm{~W}$. Depending upon the applications the size of the panels may vary but with the decrease in size the cost per watt of the panels increases [16]. Thus, the trade off between the size and cost is a major parameter in determining the installation in the Microgrids [17]. Also, the PV generation in association with the electrical storage systems (ESS) can be used to participate in LFC.

\section{B. Micro-wind and micro-hydro turbines}

Conversion of the kinetic energy of the wind to electrical form or to other required forms has been a practice since ages. Wind power has been utilized to irrigate agricultural field and in recent years to light homes through the wind farms generating power. However, using the wind turbines for lower level of generation has been a challenge but in recent years it has been accomplished through the micro turbines with the capability of generating from watts to few kilowatts. The generalized equation as in Equation 2 for the generation of power through wind is given by:

$$
\operatorname{Power}(P)=0.5 \rho A C_{P} V^{3} N_{g} N_{b}
$$

Where, $\rho$ is the air density in $k g / \mathrm{m}^{3}, A$ is the rotor swept area in $m^{2}, C_{P}$ is the coefficient of performance, $V$ is wind velocity, $N_{g}$ is the generator efficiency and $N_{b}$ is the gearbox bearing efficiency. In the review [18], the authors have discussed about the different possibilities of the wind turbines like horizontal and vertical axis for the domestic use with the designs and their characteristics. The patent [19] discusses about savonius, the possible micro wind generation turbine for domestic and low voltage generation. In similarity to the PVs, wind also can participate in LFC but with the ESS [20].

Since ages water has been the sources of energy and life. The kinetic energy of the flowing water has been used in irrigation, powering windmills for harvesting the crops and in many other applications. With the use of water for generation of electricity with the application of a simple equation as in Equation 3, a reliable sources was aggregated in the conventional sources.

$$
P=H F g
$$

Where, $P$ is the power that can be generated in Watts with a head of height $H$ in meters and $g$ is the acceleration due to gravity in $\mathrm{m} / \mathrm{s}^{2}$. The available power is not completely harvested due to the involvement of the electromechanical units like turbines and synchronous generators. Frictional losses and other losses in the generation modules constitute a considerable sum of the generated power. However, to put hydro power in renewable resource or not has always been a matter of discussion. However, only large dams were used for generation of power due to the limitations on the efficiency of small generating units. But with recent developments in the field of micro hydro units as in [21] and [22] can be sought as a future distributed generation resources. With minimum construction requirements, generation of power using microhydro turbines can vary from watts to few kilowatts as presented on website [23], which introduces a new concept of level differential hydro turbine model for micro generation. In the designs, the flow of water can be controlled and thus the power generated can be in the sync with the power demanded. Thus, this type of generation unit increases the inertia of the grid.

\section{Biomass and diesel generators}

Largely available but scarcely used is one of the best and reliable sources of energy i.e. biomass. Use of biomass has been into production of compost, green fuels and for heat through burning [24]. Biomass is considered as one of the best sources for generation of electricity either directly or through its byproducts. Gasification of biomass [25] and then using the gases for generating electricity through the fuel cells or simply exploiting the calorific content of the biomass is a worldwide applied technique. Biomass is finding its applications in the Microgrids with time, because of the offered controllability and participation in the control methods [26]. The report [27] presents a elaborated study on the impacts of biomass being used for energy generation on environment but the studies can be utilized for other geographical locations as well. Also, due to its controllability it can be used for the development of the grid.

In the Microgrids, stable operation is highly desired as most of the sources used in the generation are intermittent. Thus, in most of the studies as in [28], wind turbines are usually 
coupled with ESSs or diesel generators to deliver controlled power output for improved efficiency. Different sizing methods and strategies are proposed by authors in their work of which using DFT is mentioned in the work by Xiao et. al. in their work [29]. Time constant of the diesel generator being low, responding to LFC is a major ability of the diesel generators. Many studies as in [30] and [31], portray the idea of using the wind or PV generation units in conjugation with the diesel units for better control and stability. When operated together, the fast response from the diesel generator mitigates the intermittent nature of the natural sources.

\section{Storage Devices}

In the world of intermittent devices the storage system plays a very important role in stabilizing and mitigating the grid frequency excursions [32]. However, the cost of the system increases with the involvement of the storage. Coordinated use of the DG sources with the storage systems also provides the controllability for LFC. Depending upon the time and purpose of use, the storage devices can vary. The most common storage systems used in the grids are batteries, fuel cells, capacitor banks with either the conventional capacitors or super-capacitors. Different tools such as ragone plots can be helpful in determining the choice of the storage used for specific purposes [33]. Batteries need charge controller for stable operation. In case where the system is $\mathrm{AC}$, use of $\mathrm{PE}$ inverters will be important. Advance PE converters also are impacting the grid with high amount of penetration of harmonics in the grid [34]. Due to perturbations, storage devices can also be shifted to capacitors where the fast response may help to achieve improved response.

\section{EFFECTS ON POWER GRIDS}

In the context of additional sources in the conventional grid, penetration of RESs needs many prior investigations and information gathering of the grid to identify the nodes of penetration. Due to the resultant low inertia it is required to identify the node of the grid where the penetration of the RES can be more effective with least effect on the grid stability [35]. As mentioned in dispersed way in the previous sections, the effects of the Microgrids on the electrical power grids can be summarized in the following points:

- Reduction of the inertia of the overall system due to the penetration of more and more renewable sources [36].

- Need for better and faster control infrastructures is increased which leads to the increment in the capital cost.

- More number of control parameters like power tapping from the sources and frequency regulation, maximum power point tracking (MPPT) and ESS management pose a major optimization challenge for the power system engineers.

- Microgrids however can be used to reduce the stress on the coventional generation sources if they are provided with secondary storages or through EVs, which may be effective in handling the frequency excursions through fast responses [37].

\section{ECONOMICS OF MICROGRIDS}

The energy management and economics of Microgrid are active fields of research which aim to minimize operating costs namely maintenance costs, fuel costs and energy purchase cost from the utility grid [38]. These formulations of optimization have been classified on the basis of objective functions, constraints, optimization types, solution approaches and tools used to solve the energy management problem. However, the cost of construction of the infrastructures also constitute a major portion in determining the overall operation and costing of the Microgrids [39].

\section{OPTIMIZATION AND CONTROL OF MICROGRIDS}

After an established infrastructure, an optimized control has a great contribution towards the stable and efficient operation of a Microgrid. The control can be exercised in both centralised [40] or decentralized control. To optimize the operations of the sources and the grid as a whole several objective functions need to be described. The objective functions in Microgrid are based on geographical area, user preferences, capacity of Microgrid, equipments installed in Microgrid, government regulations, energy storage and generation, types of tariff. However, the optimization of economic dispatch is highly recommended as stated and performed in [41] and [42]. Some of the methods are:

- Linear Programming: In [43] as a universal tool, two dispatch-optimizers are proposed for energy management system. An enhanced mixed integer linear programming (MILP) based method and improved genetic algorithm code have been developed to schedule the economic dispatch and the unit commitment of Microgrid units, furthermore a novel method has been introduced to deal with the limitations of the MILP algorithm for dealing with the non-linear power system topology constraints. In [44] a novel double-layer coordinated control approach for Microgrid energy management is proposed: the schedule layer and the dispatch layer. The schedule layer obtains an economic operation scheme based on forecasting data and the dispatch layer provides power of controllable units based on real-time data. [45] presents a two-stage optimal planning and design method for combined cooling, heat and power Microgrid system. The stage of a MILP algorithm which determines the optimal operation strategy, and the stage of genetic algorithm (GA) which used to solve the optimal dispatch problem. [46] proposes a combined sizing and energy management methodology, formulated as a leader-follower problem. The leader problem focuses on sizing which is solved using a genetic algorithm while the follower problem : the energy management issue which is solved with a MILP. In [47] the authors propose the Cost Aware Smart Microgrid Network (CoSMoNet) design approach which is based on an Integer Linear Programming ILP formulation that allow economic power transactions among SMGs.

- Nonlinear Programming: [48] presents an EMS algorithm based on mixed-integer nonlinear programming 
MINLP for MG in islanding mode by different scenarios. In [49] the authors propose a mixed integer non linear programming based consumption framework to evaluate the performance of the hybrid renewable energy system. In [50] the authors solve the operation scheduling problem in renewable powered Microgrids based on integer nonlinear programming. In [51] the problem is considered as a nonlinear mixed-integer problem which minimizes capital and annual operational cost of DER and a evolutionary strategy was developed for solving the problem. In [52] a mixed integer nonlinear optimization to solve the technical challenges is presented. A non linear model is presented in [53] and [54] the MPC problem is solved as Mixed Integer Quadratic Programming (MIQP).

- Dynamic programming: The authors proposed in [55] a dynamic programming algorithm for a energy optimization analysis and power management in Microgrids with renewable energy resources and diesel generators. In [56] the authors presented the framework of Microgrid control, and performed the long term operational planning of the Microgrid by an algorithm including optimization of the unit commitment problem by a dynamic programming model. A dynamic programming is used in [57] to solve the problem of the electricity consumption patterns in a household which modeled by a mixture of Gaussian distributions.

- Stochastic programming: In [58] an stochastic energy and reserve scheduling method with different types of demand responses, to facilitate different types of customers in reserve scheduling and energy is proposed. A multiobjective dynamic stochastic programming approach is presented in [59] to maximize comfort preferences and minimize cost. In [60] the authors proposed an improved particle swarm optimization algorithm (PSO) to solve the Microgrid electricity coordinated scheduling and day-ahead cooling. In [61] a stochastic optimization formulation in Microgrid is used. The effectiveness of this proposed approach to minimizes the power losses and the expected operational cost of the Microgrid with intermittent renewable energy resources is demonstrate.

\section{CONCLUSION AND FUTURE PROSPECTIVE}

This paper provides a detailed study of the Microgrids and their components used in the current world. Also, different test benches on which this technology is being tested and different technologies through which it can be implemented. Among all of these, conventional method and methods like blockchain are highly contradicting. However, a paper like this will help the fello researchers to grasp the knowledge of Microgrids and also direct them in specified directions based on their field of research.

\section{ACKNOWLEDGEMENT}

This work has been partly supported by the m2M-GRID project of the joint programming initiative ERA-Net Smart Grids Plus.

\section{REFERENCES}

[1] V. H. M. Quezada, J. R. Abbad, and T. G. S. Roman, Assessment of energy distribution losses for increasing penetration of distributed generation, IEEE Transactions on Power Systems, vol. 21, pp. 533 540, May 2006.

[2] T. Shimizu, K. Wada, and N. Nakamura, Flyback-type singlephase utility interactive inverter with power pulsation decoupling on the dc input for an ac photovoltaic module system, IEEE Transactions on PEs, vol. 21, pp. 12641272, Sept 2006

[3] P. H. Nguyen, W. L. Kling, and P. F. Ribeiro, Smart power router: A flexible agent-based converter interface in active distribution networks, IEEE Transactions on Smart Grid, vol. 2, no. 3, pp. 487 495, 2011.

[4] A. Kaur, J. Kaushal, and P. Basak, A review on Microgrid central controller, Renewable and Sustainable Energy Reviews, vol. 55, pp. 338345,2016

[5] World Bank (Last Visited: 16/11/2018) from https://data.worldbank.org/indicator/eg.elc.accs.zs

[6] Radwan, A. A. A., \& Mohamed, Y. A. R. I. (2017). Networked control and power management of AC/DC hybrid Microgrids. IEEE Systems Journal, 11(3), 1662-1673.

[7] P. C. Loh, D. Li, Y. K. Chai, and F. Blaabjerg, Autonomous operation of hybrid Microgrid with ac and dc subgrids, IEEE Transactions on PEs, vol. 28, pp. 22142223, May 2013.

[8] Liu, X., Wang, P., \& Loh, P. C. (2011). A Hybrid AC/DC Microgrid and Its Coordination Control. IEEE Trans. Smart Grid, 2(2), 278-286.

[9] Hossain, M. J., Mahmud, M. A., Milano, F., Bacha, S., \& Hably, A. (2016). Design of robust distributed control for interconnected Microgrids. IEEE Transactions on Smart Grid, 7(6), 2724-2735.

[10] Gaztanaga, H., Etxeberria-Otadui, I., Bacha, S., \& Roye, D. (2006, November). Real-time analysis of the control structure and management functions of a hybrid Microgrid system. In IEEE Industrial Electronics, IECON 2006-32nd Annual Conference on (pp. 5137-5142). IEEE.

[11] Y. Xue, K. C. Divya, G. Griepentrog, M. Liviu, S. Suresh, and M. Manjrekar, Towards next generation photovoltaic inverters, in 2011 IEEE Energy Conversion Congress and Exposition, pp. 2467 2474, Sept 2011.

[12] J. W. Smith, W. Sunderman, R. Dugan, and B. Seal, Smart inverter volt/var control functions for high penetration of $\mathrm{pv}$ on distribution systems, in 2011 IEEE/PES Power Systems Conference and Exposition, pp. 16, March 2011.

[13] G. Pepermans, J. Driesen, D. Haeseldonckx, R. Belmans, and W. Dhaeseleer, Distributed generation: definition, benefits and issues, Energy Policy, vol. 33, no. 6, pp. 787 798, 2005.

[14] J. Jean, P. R. Brown, R. L. Jaffe, T. Buonassisi, and V. Bulovic, Pathways for solar photovoltaics, Energy \& Environmental Science, vol. 8, no. 4, pp. 12001219, 2015.

[15] W. Inam, D. Strawser, K. K. Afridi, R. J. Ram, and D. J. Perreault, Architecture and system analysis of Microgrids with peer-to-peer electricity sharing to create a marketplace which enables energy access, in 2015 9th International Conference on PEs and ECCE Asia (ICPE-ECCE Asia), pp. 464469, June 2015.

[16] A. Campanella, An analysis of the viability and competitiveness of dc Microgrids in northern india. PhD thesis, Massachusetts Institute of Technology, 2013.

[17] Bacha, S., Picault, D., Burger, B., Etxeberria-Otadui, I., \& Martins, J. (2015). Photovoltaics in Microgrids: An overview of grid integration and energy management aspects. IEEE Industrial Electronics Magazine, 9(1), 33-46.

[18] A. Tummala, R. K. Velamati, D. K. Sinha, V. Indraja, and V. H. Krishna A review on small scale wind turbines, Renewable and Sustainable Energy Reviews, vol. 56, pp. 13511371, 2016.

[19] G. Murphy, Savonius wind turbine, Mar. 20 2014. US Patent App. $14 / 007,189$.

[20] G. He, Q. Chen, C. Kang, Q. Xia, and K. Poolla, Cooperation of wind power and battery storage to provide frequency regulation in power markets, IEEE Transactions on Power Systems, vol. 32, no. 5, pp. 35593568, 2017.

[21] B. Guo, A. T. Mohamed, S. Bacha, and M. Alamir, Variable speed micro-hydro power plant: modelling, losses analysis, and experiment validation, Data processing, vol. 1, p. 0, 2018.

[22] J. Marquez, M. Molina, and J. Pacas, Dynamic modeling, simulation and control design of an advanced micro-hydro power plant for distributed generation applications, International journal of hydrogen energy, vol. 35 , no. 11 , pp. $57725777,2010$. 
[23] Turbulent (Last Visited: 16/11/2018) from https://www.turbulent.be

[24] M. Hoogwijk, A. Faaij, R. Van Den Broek, G. Berndes, D. Gielen, and W. Turkenburg, Exploration of the ranges of the global potential of biomass for energy, Biomass and bioenergy, vol. 25, no. 2, pp. 119133 , 2003.

[25] A. C. Caputo, M. Palumbo, P. M. Pelagagge, and F. Scacchia, Economics of biomass energy utilization in combustion and gasification plants: effects of logistic variables, Biomass and Bioenergy, vol. 28, no. 1, pp. $3551,2005$.

[26] P. A. stergaard, B. V. Mathiesen, B. Moller, and H. Lund, A renewable energy scenario for aalborg municipality based on lowtemperature geothermal heat, wind power and biomass, Energy, vol. 35, no. 12, pp. 48924901, 2010.

[27] M. K. Mann and P. L. Spath, Life cycle assessment of a biomass gasification combined-cycle power system, tech. rep., National Renewable Energy Lab., Golden, CO (US), 1997.

[28] C. Cecati, C. Citro, A. Piccolo, and P. Siano, Smart operation of wind turbines and diesel generators according to economic criteria, IEEE Transactions on Industrial Electronics, vol. 58, no. 10, pp. 45144525 , 2011.

[29] J. Xiao, L. Bai, F. Li, H. Liang, and C. Wang, Sizing of energy storage and diesel generators in an isolated Microgrid using discrete fourier transform (dft), IEEE Transactions on Sustainable Energy, vol. 5, no. 3, pp. 907916,2014

[30] M. Datta, T. Senjyu, A. Yona, T. Funabashi, and C.-H. Kim, A frequency-control approach by photovoltaic generator in a pv diesel hybrid power system, IEEE Transactions on Energy Conversion, vol. 26, no. 2, pp. 559571, 2011.

[31] R. C. Bansal, Automatic reactive-power control of isolated wind diesel hybrid power systems, IEEE Transactions on Industrial Electronics, vol. 53, no. 4, pp. 11161126, 2006.

[32] K. Kaur, R. Rana, N. Kumar, M. Singh, and S. Mishra, A colored petri net based frequency support scheme using fleet of electric vehicles in smart grid environment, IEEE Transactions on Power Systems, vol. 31, no. 6, pp. 46384649, 2016.

[33] T. Christen and M. W. Carlen, Theory of ragone plots, Journal of power sources, vol. 91, no. 2, pp. 210216, 2000.

[34] J. H. Enslin and P. J. Heskes, Harmonic interaction between a large number of distributed power inverters and the distribution network, IEEE Transactions on PEs, vol. 19, no. 6, pp. 15861593, 2004.

[35] G. Bhatt and S. Affljulla, Analysis of large scale pv penetration impact on ieee 39-bus power system, in 2017 IEEE 58th International Scientific Conference on Power and Electrical Engineering of Riga Technical University (RTUCON), pp. 16, Oct 2017.

[36] Debbarma, S., \& Shrivastwa, R. (2019). Inertia emulation from HVDC links for LFC in the presence of smart V2G networks. In Smart Power Distribution Systems (pp. 251-265). Academic Press.

[37] Strauss, P., \& Engler, A. (2003, May). AC coupled PV hybrid systems and Microgrids-state of the art and future trends. In Photovoltaic Energy Conversion, 2003. Proceedings of 3rd World Conference on (Vol. 3, pp. 2129-2134). IEEE.

[38] A. A. Khan, M. Naeem, M. Iqbal, S. Qaisar, and A. Anpalagan, A compendium of optimization objectives, constraints, tools and algorithms for energy management in Microgrids, Renewable and Sustainable Energy Reviews, vol. 58, pp. 16641683, 2016.

[39] D. J. Cox, Microgrid infrastructure modeling for residential Microgrids, in Power Engineering Society General Meeting, 2007. IEEE, pp. 16, IEEE, 2007.

[40] Hajar, K., Hably, A., Bacha, S., Elrafhi, A., \& Obeid, Z. (2016, July). Optimal centralized control application on Microgrids. In Renewable Energies for Developing Countries (REDEC), 2016 3rd International Conference on (pp. 1-6). IEEE.

[41] Hajar, K., Hably, A., Elrafhi, A., Obeid, Z., \& Bacha, S. (2015, October). Optimization of a Microgrid with renewable energy and distributed generation: A case study. In System Theory, Control and Computing (ICSTCC), 2015 19th International Conference on (pp. 662-665). IEEE.

[42] Ovalle, A., Ramos, G., Bacha, S., Hably, A., \& Rumeau, A. (2015). Decentralized control of voltage source converters in Microgrids based on the application of instantaneous power theory. IEEE Transactions on Industrial Electronics, 62(2), 1152-1162.

[43] M. Nemati, M. Braun, and S. Tenbohlen, Optimization of unit commitment and economic dispatch in Microgrids based on genetic algorithm and mixed integer linear programming, Applied Energy, vol. 210, pp. 944963, 2018
[44] Q. Jiang, M. Xue, and G. Geng, Energy management of Microgrid in grid-connected and stand-alone modes, IEEE Transactions on Power Systems, vol. 28, no. 3, pp. 33803389, 2013.

[45] L. Guo, W. Liu, J. Cai, B. Hong, and C. Wang, A two-stage optimal planning and design method for combined cooling, heat and power Microgrid system, Energy Conversion and Management, vol. 74, pp. $433445,2013$.

[46] B. Li, R. Roche, and A. Miraoui, Microgrid sizing with combined evolutionary algorithm and MILP unit commitment, Applied energy, vol. 188, pp. 547562, 2017.

[47] M. Erol-Kantarci, B. Kantarci, and H. T. Mouftah, Cost-aware smart Microgrid network design for a sustainable smart grid, in GLOBECOM Workshops (GC Wkshps), 2011 IEEE, pp. 11781182, IEEE, 2011.

[48] M. Marzband, A. Sumper, J. L. Domnguez-Garca, and R. GumaraFerret, Experimental validation of a real time energy management system for Microgrids in islanded mode using a local day-ahead electricity market and minlp, Energy Conversion and Management, vol. 76, pp. $314322,2013$.

[49] G. Comodi, A. Giantomassi, M. Severini, S. Squartini, F. Ferracuti, A. Fonti, D. N. Cesarini, M. Morodo, and F. Polonara, Multiapartment residential Microgrid with electrical and thermal storage devices: Experimental analysis and simulation of energy management strategies, Applied Energy, vol. 137, pp. 854866, 2015.

[50] B. Zhao, Y. Shi, X. Dong, W. Luan, and J. Bornemann, Shortterm operation scheduling in renewable-powered Microgrids: A duality-based approach, IEEE Transactions on Sustainable Energy, vol. 5, no. 1, pp. 209217, 2014

[51] T. Logenthiran, D. Srinivasan, A. M. Khambadkone, and T. S. Raj, Optimal sizing of distributed energy resources for integrated Microgrids using evolutionary strategy, in Evolutionary Computation (CEC), 2012 IEEE Congress on, pp. 18, IEEE, 2012.

[52] P. Stluka, D. Godbole, and T. Samad, Energy management for buildings and Microgrids, in Decision and Control and European Control Conference (CDC-ECC), 2011 50th IEEE Conference on, pp. 51505157, IEEE, 2011.

[53] F. Garcia and C. Bordons, Regulation service for the short-term management of renewable energy Microgrids with hybrid storage using model predictive control, in Industrial Electronics Society, IECON 2013-39th Annual Conference of the IEEE, pp. 79627967, IEEE, 2013.

[54] F. Garcia and C. Bordons, Optimal economic dispatch for renewable energy Microgrids with hybrid storage using model predictive control, in Industrial Electronics Society, IECON 2013- 39th Annual Conference of the IEEE, pp. 79327937, IEEE, 2013.

[55] T. A. Nguyen and M. L. Crow, Optimization in energy and power management for renewable-diesel Microgrids using dynamic programming algorithm, in Cyber Technology in Automation, Control, and Intelligent Systems (CYBER), 2012 IEEE International Conference on, pp. 1116 , IEEE, 2012

[56] H. Kanchev, V. Lazarov, and B. Francois, Environmental and economical optimization of Microgrid long term operational planning including pv-based active generators, in PEs and Motion Control Conference (EPE/PEMC), 2012 15th International, pp. LS4b2, IEEE, 2012.

[57] H. Hino, H. Shen, N. Murata, S. Wakao, and Y. Hayashi, A versatile clustering method for electricity consumption pattern analysis in households, IEEE Transactions on Smart Grid, vol. 4, no. 2, pp. 10481057 , 2013.

[58] A. Zakariazadeh, S. Jadid, and P. Siano, Smart Microgrid energy and reserve scheduling with demand response using stochastic optimization, International Journal of Electrical Power \& Energy Systems, vol. 63, pp. 523533, 2014

[59] C. S. Ioakimidis, L. J. Oliveira, K. N. Genikomsakis, and P. I. Dallas, Design, architecture and implementation of a residential energy box management tool in a smartgrid, Energy, vol. 75, pp. 167181, 2014.

[60] Z. Bao, Q. Zhou, Z. Yang, Q. Yang, L. Xu, and T. Wu, A multi timescale and multi energy-type coordinated Microgrid scheduling solutionpart ii: optimization algorithm and case studies, IEEE Transactions on Power Systems, vol. 30, no. 5, pp. 22672277, 2015.

[61] W. Su, J. Wang, and J. Roh, Stochastic energy scheduling in Microgrids with intermittent renewable energy resources, IEEE Transactions on Smart Grid, vol. 5, no. 4, pp. 18761883, 2014. 